\title{
Prolonged-Release Granules for Oral Suspension in Sachet
}

National Cancer Institute

\section{Source}

National Cancer Institute. Prolonged-Release Granules for Oral Suspension in Sachet. NCI

Thesaurus. Code C149874.

Medicinal product consisting of prolonged-release granules for oral suspension

presented in a sachet. 